\title{
MISPLACED AND MIGRATED IUCD: A CASE REPORT
}

R. Sankareswari ${ }^{1}$, Indira ${ }^{2}$, Geetha $\mathrm{K}^{3}$, Vani $\mathrm{S}^{4}$

\section{HOW TO CITE THIS ARTICLE:}

R. Sankareswari, Indira, Geetha K, Vani S. "Misplaced and Migrated IUCD: A Case Report". Journal of Evolution of Medical and Dental Sciences 2014; Vol. 3, Issue 25, June 23; Page: 7031-7035,

DOI: $10.14260 /$ jemds/2014/2855

ABSTRACT: Misplaced IUCD is the condition when the tail of IUCD is not seen through the cervical os. IUCD migration subsequent to uterine perforation is an uncommon but serious complication. Incidence of perforation varies from 1-3 per 1000 insertions. ${ }^{4} 24$ years old female, P3L2A0 with the complaints of severe dysmenorrhea for 4years and abdominal pain with low back pain for 2years. She had 2FTND and IUCD inserted 6months after last delivery in April 2007. 5months later, with 2months amenorrhea, diagnosed as pregnancy with expulsion of IUCD, as there was no thread seen through external cervical os. USG was not done. This pregnancy was terminated at 7 th month due to Anencephaly in February 2008. Interval laparoscopic sterilisation done in July 2010. USG on 28/09/2013 revealed IUCD in right ovary when she went for ovum donation and advised removal. After 7.5 years, on 11/10/2013 laparoscopic removal of IUCD done from right ovary which was surrounded by adhesions and pus. Perforated site seen in the fundus of uterus as depression. Appropriate antibiotics given. Post-operative period was uneventful. On follow up, the patient is free of abdominal pain and back pain. This case report highlights the need for vigilance in misplaced IUCD. Plain X ray abdomen and pelvis can pick up the diagnosis and exclude the perforation and migration. So that further complications and morbidity are prevented.

KEYWORDS; Perforation, migration, misplaced IUCD, laparoscope.

INTRODUCTION: Misplaced IUCD is defined as the condition when the tail of IUCD is not seen through the cervical os ${ }^{2}$. IUCD migration subsequent to uterine perforation is an uncommon but with serious complication. Incidence of perforation varies from 1-3 per 1000 insertions. $^{4}$

CASE REPORT: 24 years old female, P3L2A0 admitted with the complaints of severe dysmenorrhea for 4 years and abdominal pain with low back ache for 2 years. Menstrual cycles were regular with severe pain. She had 2FTND and IUCD inserted 6months after last delivery in April 2007. 5 months later, with 2months amenorrhea, diagnosed as pregnancy with expulsion of IUCD, as there was no thread seen through external cervical os.

USG was not done. This pregnancy was terminated at $7^{\text {th }}$ month due to Anencephaly in February 2008. Interval laparoscopic sterilization done in July 2010. She was suffering with lower abdominal pain for which USG done in 2012 and did not diagnose missed IUCD. USG on 28/09/2013 revealed IUCD in right ovary when she went for ovum donation and advised removal. Plain X ray abdomen and pelvis with sound insitu confirmed the diagnosis.

After 71/2 years post insertion, laparoscopic removal of IUCD was done on 11/10/2013. IUCD was embedded in the right ovary and was surrounded by adhesions and pus. Perforated site seen in the fundus of uterus as depression. Appropriate antibiotics given. Post-operative period was uneventful. On follow up, the patient is free of abdominal pain and back pain. 


\section{DISCUSSION:}

Definition: Misplaced IUCD is defined as the condition when the tail of IUCD is not seen through the cervical os. Causes are Uterus has enlarged through pregnancy, Thread has curled inside the uterus, Perforation has occurred or IUCD is buried in the myometrium and it has been expelled.2 ${ }^{2}$ This case report is misplacement due to perforation.

Incidence: The incidence of perforation varies from 1-3 per 1000 insertions which is affected by the IUD type, timing of insertion, related to pregnancy termination, position of uterus, insertion technique, experience of operator and follow-up period. ${ }^{4}$

Mechanism: In non-pregnant state spontaneous perforation may also occur with IUCD. IUCD may also perforate the wall of the uterus but remains within the myometrium. At times it perforates the entire thickness of the myometrium and either lies freely in the peritoneal cavity or more often gets embedded in the abdominal viscera. ${ }^{3}$ The mechanism and etiology of IUCD perforation and translocation to sites far from uterine cavity remains controversial.

In addition to a primary perforation at the time of IUCD insertion, complete extrusion of IUCD through the myometrium may be aided by spontaneous uterine contraction and hydrostatic negative pressure differences between the low intraperitoneal pressure and relatively higher intrauterine pressure. The migration and movement of the device in the peritoneal cavity may also be aided by the contraction of other abdominal viscera i.e. urinary bladder and small and large intestines.

Another possible mechanism for migration of the extra uterine IUCD is movement of the peritoneal fluid. ${ }^{4}$ In the present case, it seems that IUD had perforated the uterus at the time of its initial insertion as at that time, the patient was in lactational amenorrhea which is a high risk for IUD perforation due to small uterus.

Investigations: In any instance of missing IUCD, an abdominal X-Ray, USG and hysteroscopy is indicated to exclude perforation and migration. A plain radiograph or pelvic ultrasound will show whether the IUCD is still inside or has been expelled. If it is inside, the uterine sound or another IUCD inserted in the uterine cavity will show on the radiograph its proximity to the misplaced IUCD, as in Fig. 2 and perforation can be diagnosed. Abnormal shape or location of IUCD on radiograph indicates likely perforation.

Hysteroscope is useful to locate and for retrieval. Shirodkar's hook, a curette can be used for removal. In case of perforation, laproscopy is needed because copper T cause considerable tissue response and adhesions to the omentum or intestines and cannot be retrieved through laproscope some-times. ${ }^{2}$ Perforation is often suspected or diagnosed when the IUD string is no longer visible at the external os. ${ }^{6}$

Treatment: Copper containing devices have been shown to cause considerable tissue response, translocation to the peritoneal cavity may provoke peritoneal or omental adhesions, volvulus, uterocutaneous fistula and bowel perforation, which involves significant morbidity. The treatment of migrated intrauterine device is surgical either laparoscopy or laparotomy and it should not be left inside abdominal cavity. ${ }^{6}$ 
Cases have been reported with missed IUCD placed in the appendix,1,4 Migrated to sigmoid colon, ${ }^{6}$ and to rectum, ${ }^{1}$ bladder which needed appropriate surgery either by laparoscopy or laparotomy like appendectomy, colostomy, suturing of bowel injury etc.

Prevention: In order to prevent the delayed diagnosis and morbidity, the patients with intrauterine device should be alerted about the possibility of its migration and importance of regular selfexamination for missing threads which is useful for early detection of migration of intrauterine device.

In prospective descriptive study, the placement of IUCD has been described. ${ }^{5}$ Ultrasound scanning of the uterus included a true longitudinal section to visualize the entire length of the endometrial cavity. The distance from the superior edge of IUD to the internal uterine wall in sagittal plane was measured (D), as fig. $\mathrm{D}=\mathrm{A}-\mathrm{B}$. $\mathrm{A}=$ the distance from the superior edge of IUD to the outer edge of the uterine fundus. $\mathrm{B}=$ the myometrial thickness.

Definition of the IUD misplacement was D $>3 \mathrm{~mm}$ at immediate post insertion. The downward displacement was defined as an increase of more than $5 \mathrm{~mm}$ of the $\mathrm{D}$ in one or more measurement from the initial location. Expulsion defined as visible protrusion of the stem of IUD through the external cervical os. The IUD was defined as cervically located when the vertical stem was found to lie completely in the cervical canal. 5

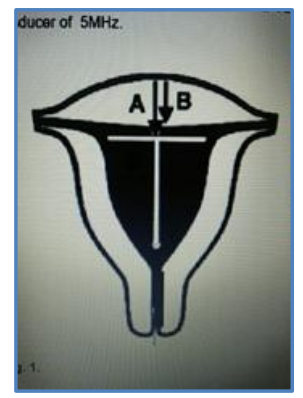

CONCLUSION: This case report highlights the need for vigilance in misplaced IUCD. Plain X ray abdomen and pelvis can pick up the diagnosis and exclude the perforation and migration. So that further complications and morbidity are prevented.

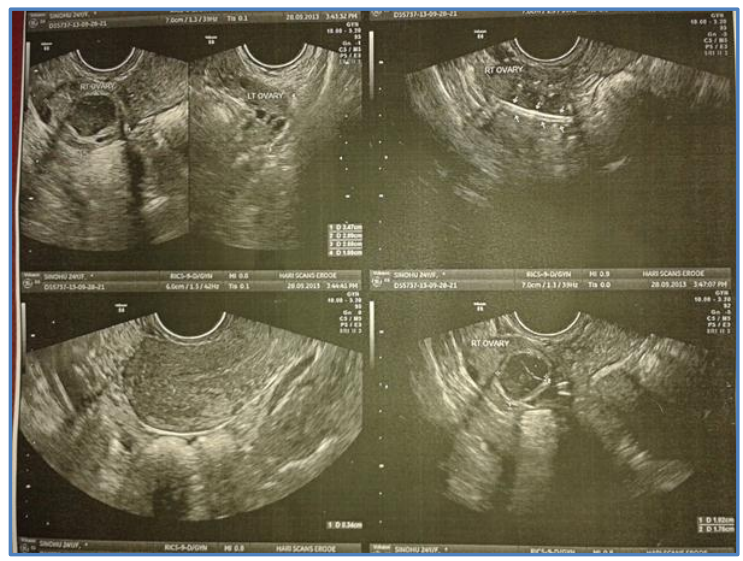

Fig. 1: TVS - USG -Empty uterine cavity, Normal left ovary, Right ovary with IUCD and pus. 


\section{CASE REPORT}
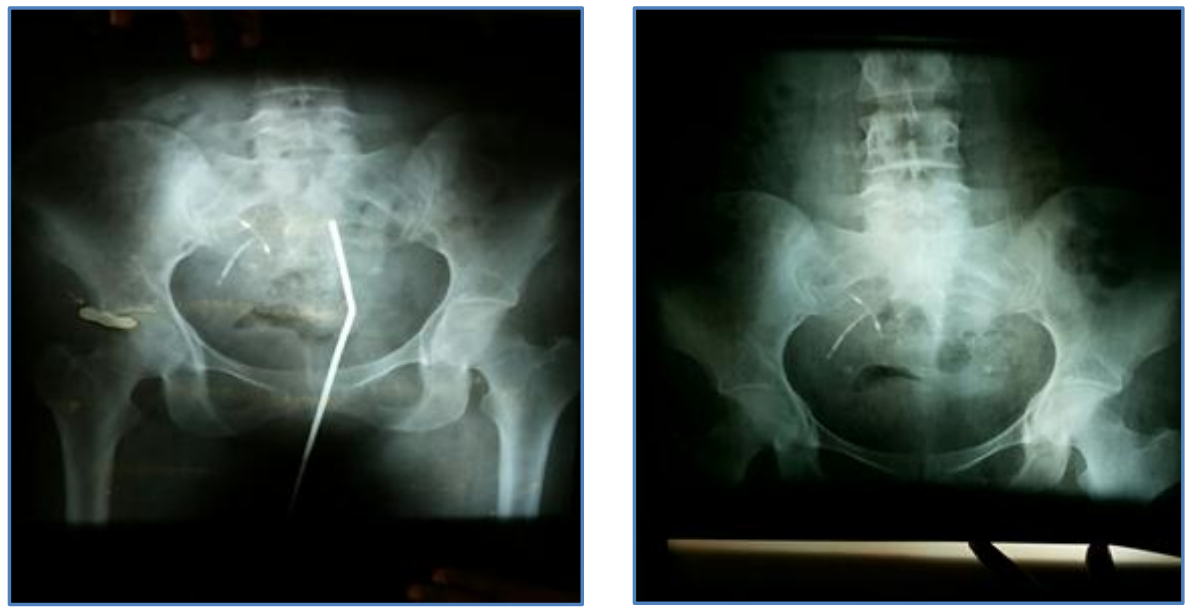

Fig. 2: plain $\mathrm{x}$-ray abdomen showing sound insitu, abnormal shape and position of IUCD

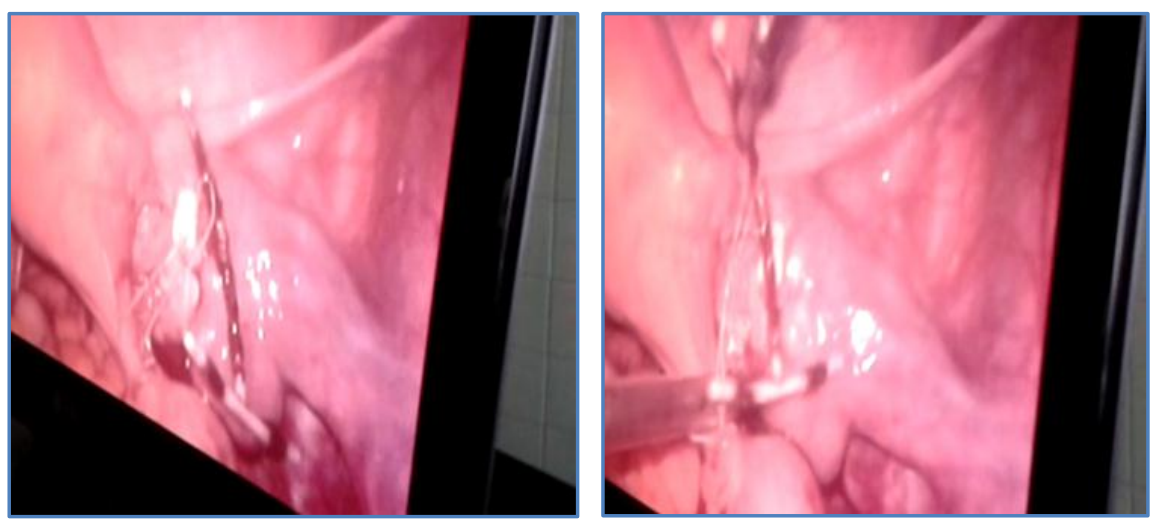

Fig. 3: laprascopic view showing IUCD in the right ovary

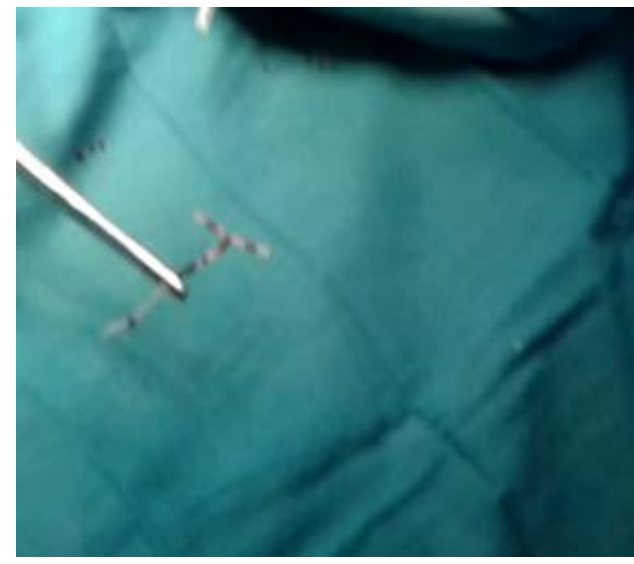

Fig. 4: Copper IUCD Removed 


\section{REFERENCES:}

1. Aruna Nigam, Ratna Biswas, Archana Mishra. Misplaced intrauterine contraceptive device: an enigma. Case series - Open Access Journal of Contraception; 15 December. 2010.

2. Howkins and Bourne; Birth control and medical termination of pregnancy, Shaw's text book of Gynaecology; 15th ed. editors. V G Padubidri, S N Daftry Elsevier: 2011. p. 229 - 230.

3. Ibid, 169.

4. S.R. Singhal, D.S. Marwah, A. Paul, S.K. Singhal. Missed Intra Uterine Device: A Rare Indication for Appendicectomy Review of Literature. East and Central African Journal of Surgery. July/August 2010; Volume 15: Number 2.

5. Thai Orawan Tangtongpet MD, Wicharn Choktanasiri MD, Sanya Patrachai MD, Nathpong Israngura Na Ayudhya MD. Intrauterine Location and Expulsion of Intrauterine Device. Journal of Obstetrics and Gynaecology. March 2003; Vol. 15: p. 45 -50.

6. Ü. S. Nceboz, H. T. Özçakir, Y. Uyar and H. Ça]lar. Migration of an intrauterine contraceptive device to the sigmoid colon: a case report. The European Journal of Contraception and Reproductive Health Care 2003; p. 229-232.

\section{AUTHORS:}

1. R. Sankareswari

2. Indira

3. Geetha K.

4. Vani S.

\section{PARTICULARS OF CONTRIBUTORS:}

1. Associate Professor, Department of Obstetrics and Gynaecology, Sri Venkateswara Medical College, Pondicherry.

2. Assistant Professor, Department of Obstetrics and Gynaecology, IRT-Perundurai Medical College, Erode.

3. Tutor, Department of Obstetrics and Gynaecology, IRT-Perundurai Medical College, Erode.

4. Tutor, Department of Obstetrics and Gynaecology, IRT-Perundurai Medical College, Erode.

\section{NAME ADDRESS EMAIL ID OF THE CORRESPONDING AUTHOR:}

Dr. R. Sankareswari, Associate Professor, Sri Venkateswara Medical College, Pondicherry, Pincode - 605102. Email: mlrsreekrishna@yahoo.com

Date of Submission: 11/06/2014.

Date of Peer Review: 12/06/2014.

Date of Acceptance: 19/06/2014.

Date of Publishing: 21/06/2014. 